\title{
Seismic features of vibration induced by train*
}

\author{
CHEN Qi-fu LI Li CHEN Yong \\ (Institute of Earthquake Science, China Earthquake Administration, Beijing 100036, China)
}

\begin{abstract}
Based on schematically formulation of the vibrations induced by moving trains, this paper analyses the waveforms along the Datong-Qinhuangdao railroad in Northern China recorded in the suburban Huairou district of Beijing on March 8, 2003. It is illustrated that vibrations induced by train, except traditional recognized noises and interference effects, could be used as a seismic source to detect crustal structures with its advantage of abundant frequency spectrum, repeatability and no additional harm to the environment. It will bring lights to the traditional exploration seismology with the further studies of signal processing and interpretation methods, and related models and new observing systems.
\end{abstract}

Key words: vibration induced by trains; moving sources; seismic features

\section{Introduction}

Collisions can be generated continuously by the passage of trains due to the surface irregularities of wheels and rails. When a fully loaded train or freight with weight of thousands tons runs on deformed rails, it may induce strong vibrations. Such vibrations may transmit several kilometers to result in building damage. For instance, the famous Longmen Grottoes near the Luoyang city in China has been seriously damaged by the ground trembling by trains pasting near it (http://www.earthquake.net.cn/science/eerc/), while in Italy, railroads were meticulously designed to avoid influence of ground trembling by trains on the ancient city of Venice and the leaning tower of Pisa. A large amount of research work on the damage and influence of vibration induced by running trains (VIRT) on buildings and structures have been done in Japan, Europe and USA in recent years, and the significant progresses in VIRT observation and simulation were made since 1970s (Gutowski, Dym, 1976; Melke, Kraemer, 1983; Okumura, Kuno, 1991; Heckl, et al, 1996; ZHAI, 2001; WANG, 1999; XIA, et al, 1999; Hung, Yang, 2001a). Okumura and Kuno (1991) studied the effects of various factors on railway noise and vibration through a regression analysis of field data obtained from 79 sites along 8 traditional railway lines in an urban area in Japan. Among the six factors they used to explain the vibration peak levels, i.e., the distance, railway structure, train type, train speed, train length and background vibration, they found that the influence of distance was the greatest, but the influence of train speed (generally under $100 \mathrm{~km} / \mathrm{h}$ ) was not very significant. All this kind of researches focus on the response spectrum of constructions, and is conducted mainly with accelerometer measurements along railroads.

Foundation item: National Natural Science Foundations of China (No. 40234038 and 40174014 ). 


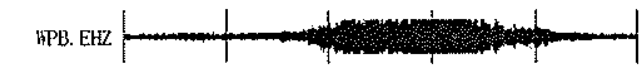

(a)

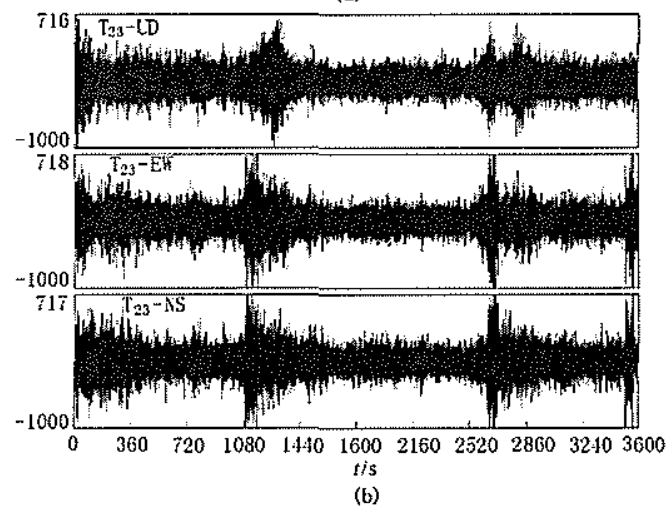

Figure 1 Vertical recordings of VIRT at WPB Watts Point, BC, Canada (http://www.pgc.nrcan. gc.ca/seismo/seismos/interpret.htm) (a) and at Tanggu seismic station T23 of China (b)
In the early time, earth scientist already knew that VIRT could interfere with the seismograph records on earthquake stations near the railroad, and were adopted to design guidelines for site selection of seismic station (Willmore, 1979). There are express provisions in China that the seismograph station should avoid arterial railways (State Seismological Bureau, 1990; China Seismological Bureau, 2001). If the railway and seismometer lie on different geological regions or there are mountains or river valleys between them, the seismometers should be located at $3 \mathrm{~km}$ away from the railroad, otherwise, the distance between the seismometer and the railroad should be over $5 \mathrm{~km}$. Nevertheless, some seismograph station still could record VIRT usually, both in China and other countries. For instance, VIRT is

semi-periodically recorded (Figure 1a) by a short period seismograph with a single component (S13) located at WPB Watts Point, British Columbia, Canada $\left(49.657^{\circ} \mathrm{N}, 123.210^{\circ} \mathrm{W}\right.$, elevation $0.273 \mathrm{~km}$ ). Another example (Figure $1 \mathrm{~b}$ ) is from Tanggu seismic station of China $\left(39.05^{\circ} \mathrm{N}, 117.52^{\circ} \mathrm{E}\right)$, named as $\mathrm{T} 23$, deployed with a 3-component borehole short-period seismometer (FSS-3DBH) at the depth of $0.275 \mathrm{~km}$. Almost former studies related to VIRT concentrated on its perturbation and harm, that is, concerning VIRT as a harmful noise and vibration source, but less investigation to take such kind of repeated exciting signal as an information source to inverse crustal structures. Ditzel, et al (2001) shows that VIRT could be expressed by terms of reflection and transmission properties of the stratified structure with modeling train as an oscillating point force (Figure 2). Up to now, however, it is impossible to identify the deepest layer VIRT may reach. The running

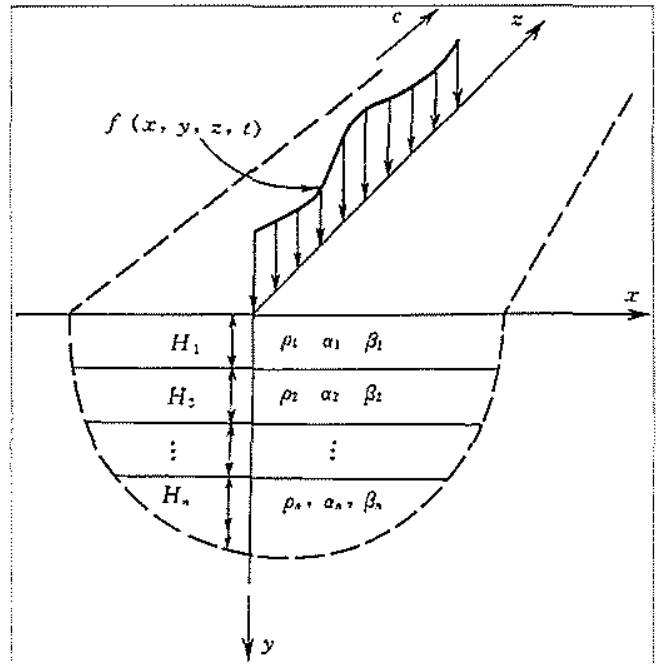

Figure 2 Typical model of VIRT problem (modified from Yang et al, 2003) train with wheel sets could be viewed as a sequence of moving point sources. Even more, no records about VIRT measured with distance of several kilometers perpendicular to the track are published until now. This paper brief summarized some theoretical and simulation results of VIRT. In order to further investigate the theoretical wave field with field experiments of VIRT, the present paper performed essential analyses of waveforms with a field measurement in suburban of Beijing along a heavy-load railway. 


\section{Generalization of VIRT formulation and simulation}

The problem of vibration induced by train through rail track, sleeper, rail pad and embankment to be considered is schematically shown in Figure 2, where a train moving at speed $c$ is traveling along the $z$-axis on a homogeneous stratum surface. The external loading generated by a moving train is simulated as a moving load of frequency $f_{0}$ traveling with speed $c$ along the $z$-axis on the surface (Yang, et al, 2003), i.e.

$$
f(x, y, z, t)=\delta(x) \delta(y) \phi(z-c t) \mathrm{e}^{\mathrm{i} 2 \pi f_{0} t}
$$

where the exponential term accounts for the dynamic effect resulting from the rail irregularity or mechanical system of the vehicles, and $\phi(z)$ represents the loading function caused by the axle loads of all carriages of the train, which can be obtained as the superposition of the loading function $q_{0}(z)$ for each axle load shown in Figure 3. Here, the axle loading function

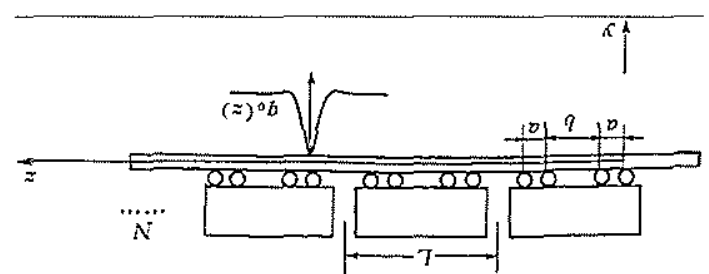

Figure 3 Schematic of train induced loadings (Yang, et al, 2003)(图贴反了, 应转 180 度) $q_{0}(z)$ is determined from the deflection curve of an infinite elastically supported beam with a point load $T$ applied on the surface. Assume the flexural rigidity of the beam to be $E_{I}$ and the foundation stiffness to be $s\left(\mathrm{~N} / \mathrm{m}^{2}\right)$, the loading function $q_{0}(z)$ can be expressed as (Yang, et al, 2003; Hung, Yang, 2001b; Esveld, 1989):

$$
q_{0}(z)=\frac{T}{2 \alpha} \mathrm{e}^{\frac{-1-1}{\alpha}}\left[\cos \left(\frac{|z|}{\alpha}\right)+\sin \left(\frac{|z|}{\alpha}\right)\right]
$$

where $\alpha$ is the characteristic length of the beam

$$
\alpha=\sqrt[4]{\frac{4 E_{I}}{S}}(\mathrm{~m})
$$

If the dynamical interactions of wheels and rails caused by different track junctions, oblate wheel and roughness rail are considered, we have to deal with very complicated coupling dynamical problems (WANG, 1999). There are some researches related to those problems in locomotive dynamics, rail dynamics and interaction of wheels and rails, but it is needed to further develop to be applied in real problems.

In a semi-infinite elastic space (Figure 2), each of the layer is characterized by its density $\rho_{n}$ and by the compressional (P) and shear (S) wave velocities $\alpha_{n}$ and $\beta_{n}(n=1,2, \cdots, N)$. For each of the $n$th layers, the equation of motion and the constitutive relation hold (Esveld,1989):

$$
\begin{array}{cc}
\frac{\partial \tau_{i j}(w)}{\partial w_{i}}+\omega^{2} \rho_{n} u_{i j}(w)=-f_{j}(w) & (i=1,2,3 ; j=1,2,3) \\
\tau_{i j}(w)=\lambda_{n} \delta_{i j} \frac{\partial u_{k}(w)}{\partial w_{k}}+2 \mu_{n} \frac{\partial u_{j}(w)}{\partial w_{i}} & \left(y_{n-1}<w_{2}<y_{n}, n=1,2, \cdots, N\right)
\end{array}
$$

where $u$ is the displacement and $\tau$ the stress tensor. Furthermore, $y_{n}$ is the $n$th interface, $y_{0}$ is the 
free surface co-ordinate and $w$ a position vector given by $w=w_{1} i_{1}+w_{2} i_{2}+w_{3} i_{3}$ and $\omega$ is the angular frequency of the Fourier transform. In equation $(4), f_{j}$ is the loading force of a moving train given in equation (1).

Jones et al (2000) assumed that the railroad structure is modeled as a $2 \mathrm{~m}$ layer of weathered sandstone overlying the elastic half-space. With given Young's modulus, Poisson ratio and structure parameters of media density and velocities of $\mathrm{P}, \mathrm{S}$ and Rayleigh waves for the elastic half-space, their simulation for $50 \mathrm{~m} \times 50 \mathrm{~m}$ area within the track showed quite different responses of the ground surface to loads at three frequencies for trains traveling at speed of $144 \mathrm{~km} / \mathrm{h}$. High levels of vibration may be expected to occur with higher frequency of excitation. With same oscillating frequency of the load to different structure parameters, however, different propagation effects of the ground surface can be generated by different train speeds. Waves of significant amplitude on the ground surface appear as the train speed approaches and exceeds the shear wave speed in the upper layer. The induced vibration has a low rate of decay with distance for the shorter wavelength wave (higher frequency).

Yang et al (2003) investigated parametrically the effect of soil properties on the transmission of vibrations due to high-speed moving trains with finite/infinite element approach. The parameters to be considered include the shear wave velocity, damping ratio and layer thickness of soils, train speed and vibration frequency of moving trains. They designed a mesh system to cover a width of $20 \mathrm{~m}$ and a depth of $10 \mathrm{~m}$ with different elements for the near and far field of the system. The simulation concluded that the soil damping has an important effect on the degree of attenuation, and the stratum depth is a key factor for vibration propagation. The rail structure could be determined based on the relationship (Yang, et al, 2003) of critical frequency $f_{\mathrm{cr}}$, train speed $c$, vibration frequency $f_{0}$ of the moving loads and the velocity of Rayleigh wave $C_{\mathrm{R}}$ of the top layer

$$
f_{\mathrm{cr}}=\frac{f_{0}}{1 \pm \frac{c}{C_{\mathrm{R}}}}
$$

Because no waves can propagate outward with lower critical frequency (Yang, et al, 2003), the Rayleigh velocity $C_{R}$ of the top layer in layered structure can be determined theoretically from the critical speed at the location near the source with $f_{0}=0$.

By expressing three-dimensional field in terms of reflection and transmission properties of the layers, the response generated by a moving train was computed numerically (Ditzel, et al, 2001) based on a representation of the wavefield in the slowness domain. The predicted vibrations from the theoretical model showed a good agreement with the data of the field measurement, and quite similarity with the recordings of traditional explosion. They also pointed out that vibrations due to an oscillating load could be observed at rather large distances, even if the train speed is smaller than the critical wave (Rayleigh wave) speed.

\section{Analysis of experimental recordings}

\subsection{The field experiment}

In order to explore the possibilities to detect the ground structures with the seismograph records of VIRT, we did a field observation in suburban of Beijing along a heavy-load railway from Datong city to Qinhuangdao city in the spring of 2003 with broadband and short-period seismographs. 


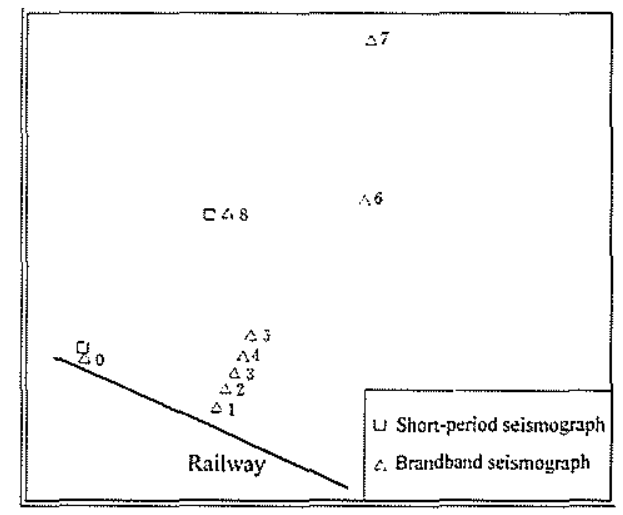

Figure 4 Field observation system for vibration induced by running trains on March 8, 2003
The Datong-Qinhuangdao electric railway is a major coal transport route with a designed capacity of ten thousand tons. The frequent passages on the railway are freight trains (heavy-loaded from Datong to Qinhuangdao, but back with empty cargos), occasionally by locomotive engines and short-distance passenger trains. The freight train is possible to carry coals over 6000 tons with its own weight more than 1000 tons. The measurement field is located near Taipingzhuang village $\left(116^{\circ} 41^{\prime} \mathrm{E}, 40^{\circ} 16^{\prime} \mathrm{N}\right)$ in the suburban Huairou district of Beijing. Figure 4 shows the observation area $\left(116.68^{\circ} \sim 116.71^{\circ} \mathrm{E}, \quad 40.26^{\circ} \sim 40.28^{\circ} \mathrm{N}\right)$ with a NE124 segment of the Datong-Qinhuangdao

railway in the southwest. There are two countryside pavements, but no public road across the measurement field, and it is rarely to see automobile passing the pavements during our experimental observation. There is a professional service station in Chawu with the distance of around $12 \mathrm{~km}$ to the experimental field. The passing speeds of the empty trains, the heavy freight train and the passenger train are about $60 \mathrm{~km} / \mathrm{h}, 70 \mathrm{~km} / \mathrm{h}$ and $80 \mathrm{~km} / \mathrm{h}$ respectively because all trains must stop on the Chawu station for maintaining.

The observation sites of 00t and 08t (Table 1 and Figure 4) are cement ground surface, and others belong to excavated solid soil. Table 1 lists the sites where we deployed the seismographs and related observation parameters, in an order of the distance from the site to the railway. Two sets of broadband seismographs were used, including seismometers with band from $0.05 \mathrm{~Hz}$ to 20 $\mathrm{s}$ and 24-bit multi-channel digitized data acquisition recorders, and one set of JC-V100 short-period seismograph, including a seismometer with band from $1 \mathrm{~Hz}$ to $80 \mathrm{~Hz}$ and a 16-bit data acquisition recorders. The two sets of broadband seismographs are deployed alternately in different sites while vibrations induced by 2 or 3 passing trains are well recorded. Both short-period and broadband seismographs are fixed on site 00t more than 2 hours for comparison analysis.

\subsection{Time-domain features of VIRT}

Figure 5 illustrated the three component seismograms for the passing locomotive engine on $13 \mathrm{~h} 30 \mathrm{~min}$ and heavy-loaded train on $13 \mathrm{~h} 47 \mathrm{~min}$ recorded at site $00 \mathrm{t}$ by short-period and broadband seismographs from $13 \mathrm{~h} 28 \mathrm{~min}$ to $13 \mathrm{~h} 49 \mathrm{~min}$. It is demonstrated significantly the similarities and differences between locomotive waveform (less than $20 \mathrm{~s}$ ) and heavy-loaded train's (more than 48 s). The essential resemblance of broadband and short-period VIRT recordings was clearly exhibited. The analysis in this paper only focuses on Z-component because of the satisfied similarities of three components and the significant amplitude of vertical vibration. The waveforms in Figure 6 show obviously that the signal noise ratio $(\mathrm{S} / \mathrm{N})$ of the ground shakings decreased with distance, although no recordings from the same heavy-loaded train. The $\mathrm{S} / \mathrm{N}$ with several tens at the site of $3 \mathrm{~m}$ decreased to 5 at the site of $500 \mathrm{~m}$, then to about 2 at the site of $2.15 \mathrm{~km}$ from the railway. There is definite automobile disturbance for the sites $006 \mathrm{t} \sim 008 \mathrm{t}$, but the

Table 1 List of observation sites 


\begin{tabular}{|c|c|c|c|c|c|}
\hline Site & $\varphi_{\mathrm{N}} /\left(^{\circ}\right)$ & $\lambda_{E} /\left(^{\circ}\right)$ & $\begin{array}{l}\text { Distance between the } \\
\text { site and the railway/m }\end{array}$ & Seismograph & $\begin{array}{l}\text { Observing period } \\
\text { h:min }\end{array}$ \\
\hline \multirow[t]{2}{*}{$00 \mathrm{t}$} & 40.270 & 116.684 & 3 & Short-period & $11: 24-16: 50$ \\
\hline & & & & Broadband 1 & $11: 24 \sim 14: 10$ \\
\hline $01 \mathrm{t}$ & 40.268 & 116.692 & 100 & Broadband 2 & $11: 50 \sim 14: 42$ \\
\hline $02 \mathrm{t}$ & 40.269 & 116.693 & 200 & Broadband 1 & $14: 40 \sim 15: 35$ \\
\hline $03 t$ & 40.269 & 116.694 & 300 & Broadband 2 & $15: 35 \sim 16: 03$ \\
\hline $04 \mathrm{t}$ & 40.270 & 116.694 & 400 & Broadband I & $15: 54 \sim 16: 45$ \\
\hline $05 \mathrm{t}$ & 40.271 & 116.695 & 500 & Broadband 2 & $16: 41 \sim 17: 00$ \\
\hline $08 \mathrm{t}$ & 40.277 & 116.693 & 1100 & Short-period & $17: 15 \sim 18: 50$ \\
\hline $06 \mathrm{t}$ & 40.277 & 116.702 & 1650 & Broadband 1 & $17: 30 \sim 18: 30$ \\
\hline $07 \mathrm{t}$ & 40.285 & 116.702 & 2150 & Broadband 2 & {$[7: 30 \sim 18: 30$} \\
\hline
\end{tabular}

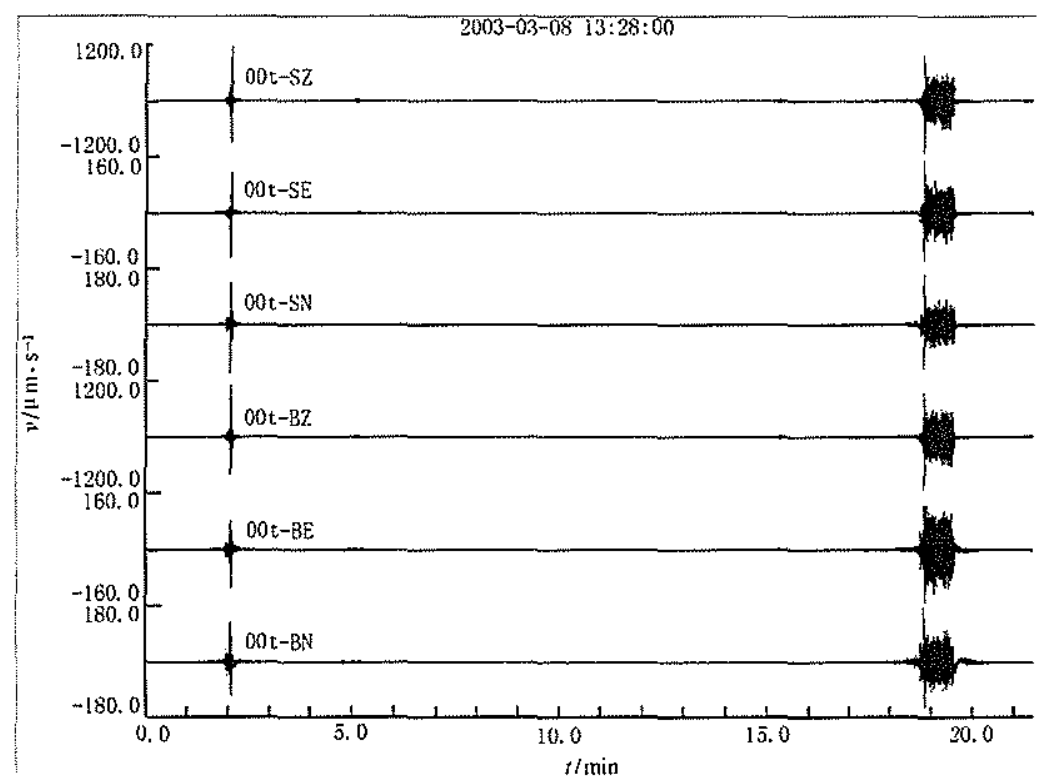

Figure 5 Short-period (S) and broadband (B) seismograph records of the vibration induced by heavy-load trains at site $00 \mathrm{t}$

$Z$ denotes vertical component, $E$ denotes $E W$ component, $N$ denotes NS component; $S Z$ and $B Z$ represent the $Z$ component of a short-period and broadband seismograph respectively. The same labels are shown in Figures $6 \sim 9$

amplitudes of the ground shakings in Figure $6 \mathrm{~b}$ decreased slowly at far field $(1.1 \sim 2.15 \mathrm{~km})$. The length of the shaking wave increases distinctly with the distance from the railway according to waveforms recorded at sites $00 t$ and $01 t$ for the identical heavy-loaded train. The experimental data, however, are insufficient to give a certain relationship of waveform length with receiver distance because it is closely related to the length and load of train, even to train speed. The peak particle velocity (PPV) about $1200 \mu \mathrm{m} / \mathrm{s}$ observed at site $00 \mathrm{t}$ for heavy-loaded trains with speed about $70 \mathrm{~km} / \mathrm{h}$ is nearly a half of PPV $2.5 \mathrm{~mm} / \mathrm{s}$ obtained at $6 \mathrm{~m}$ from the track by Degrande and Schillemans (2001) from free field vibration measurements during the passage of a Thalys high speed train (speeds varying between $223 \mathrm{~km} / \mathrm{h}$ and $314 \mathrm{~km} / \mathrm{h}$ ). It is confirmed the interdependent relationship between the vibration scale and the length, weight and speed of train in some way.

Using the reference velocity value of $v_{0}=10^{-2} \mu \mathrm{m} / \mathrm{s}$ suggested by Esveld (1989), the calculated PPV values in Figure 6 are 101.6, 84.1, 84.6, 81.6, 85.6 and $70.9 \mathrm{~dB}$ for sites $00 \mathrm{t}$ to $05 \mathrm{t}$, and 
the notable $60 \sim 80 \mathrm{~dB}$ responses for sites $06 \mathrm{t}$ to $08 \mathrm{t}$ with stated mixture noises.
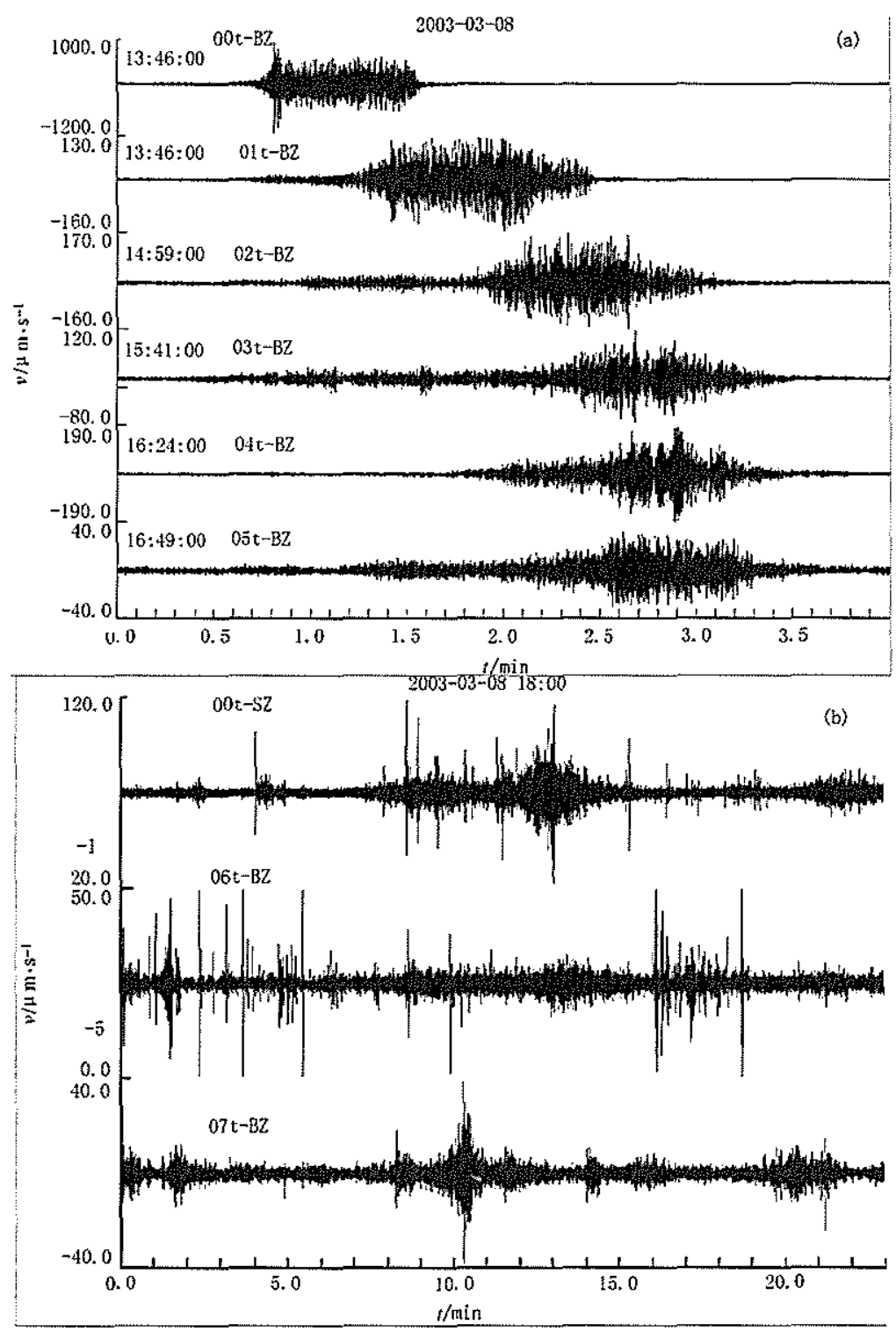

Figure 6 Records of the vibration induced by heavy-load trains at different sites

(a) The beginning record time was labeled in the top-left of each channel; (b) The beginning time is 18:00:00

\subsection{Spectral features of VIRT}

The Doppler effects of classical physics appear significantly in vibration signals induced by moving train as a multi tremble source. In Figure 7, the distinct discrepancy is showed in the frequency spectral curves of the forward and backward propagating waves, ahead and behind of the locomotive engine respectively. When the train comes to the seismograph, the peak value of high frequency is greater than it moves gradually away. 

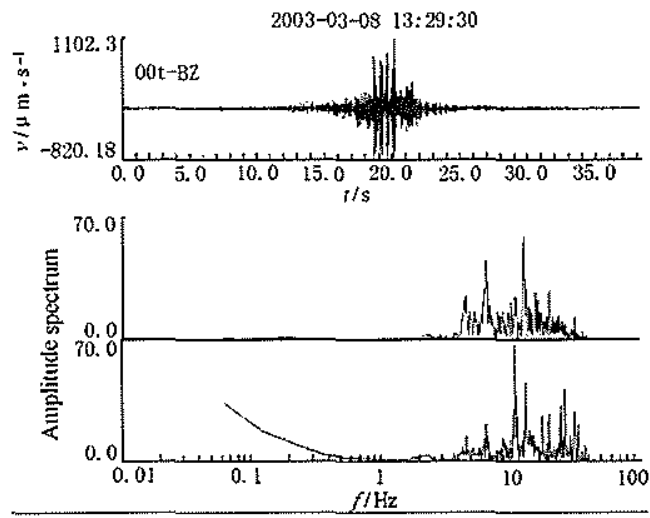

Figure 7 Broadband record at site $00 \mathrm{t}$ induced by locomotive and its amplitude spectrums before and after the passage of locomotive

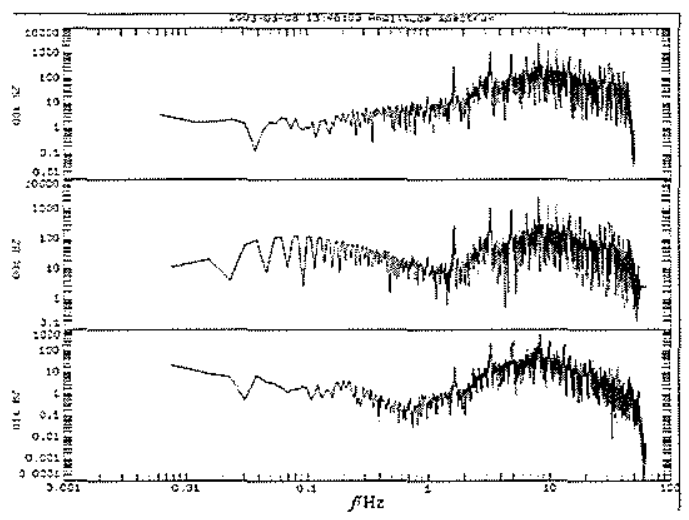

Figure 8 Amplitude spectrums of the vibration induced by heavy-load trains at sites $00 \mathrm{t}$ and $01 \mathrm{t}$

Figures 8 and 9 give the amplitude spectra of locomotive and heavy-loaded train showed in Figure 5. It is obvious that the frequency ranges recorded by short-period and broadband seismometers are nearly equivalent with mass frequency $1 \sim 20 \mathrm{~Hz}$. The spectra from 3 seismographs in sites $00 \mathrm{t}$ and $01 \mathrm{t}$ all indicate that the vibration frequency of heavy-loaded train is about $8.2 \mathrm{~Hz}$, and other distinguishable peak frequencies about 1.64, 3.27, 4.90, 6.54, 9.80, 11.44, 13.08, 14.71, $16.27,17.98 \mathrm{~Hz}$, and even at $30 \mathrm{~Hz}$. Those peak values may reflect the resonance feature of multi carriages of the train or predominant frequencies correlated to crustal structure. Those peak frequencies affirmatively appeared in Figure 10 for power spectral density calculated with 1 024 and 4096 points respectively. It is impossible to identify the passage of the individual carriages from our recordings as done by Degrande and Schillemans (2001) because the only one site is closed to the rail truck. Comparing Figure 5 with Figure 6 a, however, it is implicitly exhibited the oscillation excited by the engine and individual carriage.

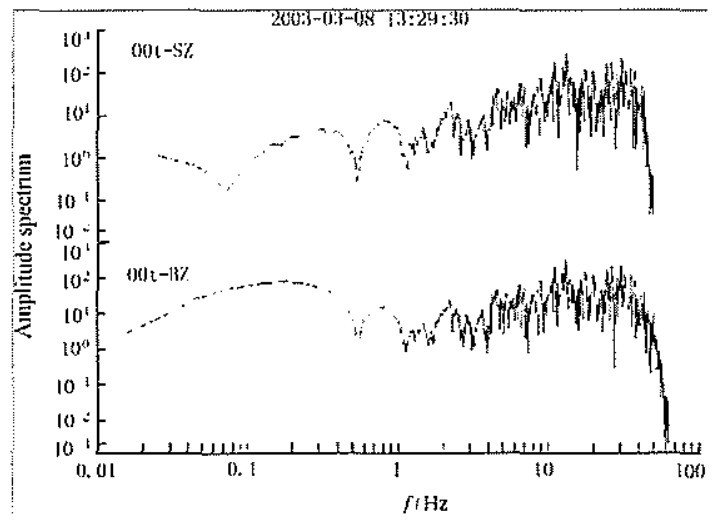

Figure 9 Amplitude spectrums of short-period and broadband records induced by locomotive at sites $00 \mathrm{t}$

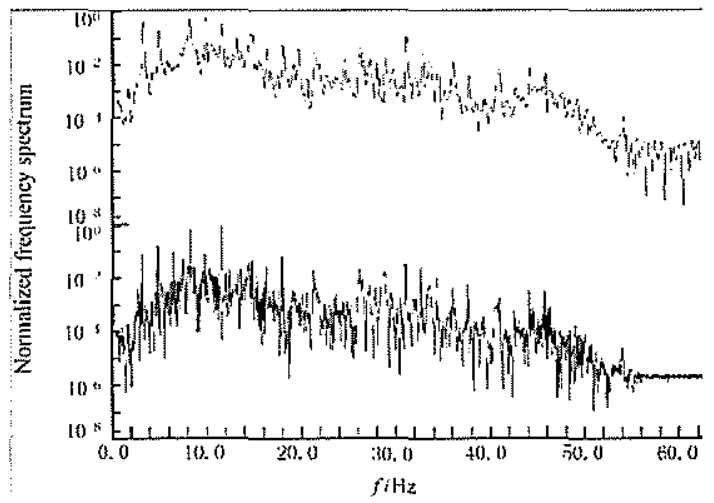

Figure 10 Power spectral density of broadband record induced by heavy-load train at sites $00 t$ 
Due to the limitation of our experimental observation, we have not observed the vibrations in different sites induced by the same train. The variable background noise in different sites extends the difficulty to distinguish the likelihood body wave what may exist in the recording. It is impossible to analytically compare our recording with the vibration response to traditional explosive source, and it is very difficult to perform further analyses based on the simulating results given by Yang et al (2003) or Jones et al (2000). Nevertheless, our experimental investigation provides a foundational exploration to shallow crustal structures with VIRT as moving seismic sources and related theoretical simulations with real observational measurement in far field.

\section{Discussion and conclusions}

Our essential analyses and the published relative results are sufficient to confirm the advantage to use VIRT as a seismic source to detect shallow crustal structures. VIRT, as a new kind of trigger source, is repeatable and stable with no additional harm to the environment and broad frequency spectrum. VIRT will provide additional approach to the traditional exploration seismology with the further studies of signal processing and interpretation methods, and related models and new observing systems.

About VIRT theoretical analysis, the multi-point moving problem is the vibrations induced by the train wheels and transmitted downward with the railway tracks, sleepers and gravel embankment. It is involved in the complicated coupling processes of train, railway and stratum. The maximums of reachable depth and measurable distance of the VIRT must be investigated further. The foundational theory of VIRT and its applicable conditions should be quantificationally clarified. There are some referencable theories in the field of engineering vibration and railway engineering, and the models of finite moving source of earthquake rupture (ZHENG, 1979; Ben-Menahem, 1961; Ide, 2002) to offer favorable background to build up the theoretical models of VIRT multi-point moving sources. However, the problem of the VIRT affected by the varied loadings of train is almost not taken into account in the published studies (Ditzel, et al, 2001; Yang, et al, 2003; Hung, Yang, 2001b; Esveld, 1989; Degrande, Schillemans, 2001; Jones, et al, 2000). It should be paid more attention in the further study.

About the processing and analysis of VIRT signals, how to inverse effectively the crustal structure or shallow structure nearby the railway, even to obtain their changes related to medium property with the variation of tectonic stress remains unsolved. The correlative analysis in frequency and time domain may be a good beginning to develop new methods for VIRT signal processing. The frequency-dependent decompositions of VIRT to get significant vibration frequencies for different train speeds and loadings are a very important way to identify and distinguish further available VIRT information. The recognition and analysis of weak signals must be applied to increase the VIRT detectability according to our experimental data in $2.15 \mathrm{~km}$ distance to the railway.

Due to most researches focus on the damage and influence of trains, their field observational data are almost within distance of $100 \mathrm{~m}$ to the railroad. VIRT recordings at distance of kilometers and/or below ground surface are rarely delivered until now. We have collected the VIRT waveforms with slow attenuation at distances $1.1 \sim 2.15 \mathrm{~km}$, although our data and the recordings in the $275 \mathrm{~m}$ borehole (Figure $1 \mathrm{~b}$ ) could not be confirmed that they contain reflected or converted waves from crustal interfaces now. However, as a brand-new research field to use VIRT as a seismic source to detect ground structures, new signal processing and interpretation methods and re- 
lated theories must be developed, and the measurable instruments must be well designed to collect more VIRT data for thorough and detail investigations.

Acknowledgements We thank Mr. ZHANG Lian and LOU Hai, Professor WANG Chun-yong, Dr. LI Juan and WANG Bao-shan, Mr. QI Cheng and LIU Ji-fu for their help in the field observation.

\section{References}

Ben-Menahem A. 1961. Radiation of seismic surface waves from finite moving sources [J]. Bull Seism Soc Amer, 51: 401 435.

China Seismological Bureau. 2001. Technical Specification for Earthquake and Geophysical Observation: Earthquake Observation (Provisional) [M]. Beijing: Seismological Press, 5 32 (in Chinese).

Degrande G, Schillemans L. 2001. Free field vibrations during the passage of a Thalys high-speed train at variable speed [J]. I Sound Vibr, 247(1): doi:10.1006/Jsvi.2001.3718, 131 144.

Ditzel A, Herman G C, Drijkoningen G G. 2001. Seismograms of moving trains comparison of theory and measurements [J]. $J$ Soumd $\mathrm{Vibr}, 248(4)$ : doi:10.1006/jsvi.2001.3807, 635 652.

Esveld C. 1989. Modern Railway Track [M]. Netherlands: MRT-Productions, 459 474.

Gutowski T G Dym C L. 1976. Propagation of ground vibration: A review [J]. J Sound Vibr, 49(2): 179 193.

Heckl M, Hauck G, Wettschureck R. 1996. Structure-borne sound and vibration from rail traffic [J]. J Sound Vibr, 193(1): 175 184.

Hung H H, Yang Y B. 200 la. A review of researches on ground-borne vibrations with emphasis on those induced by trains [J]. Proc Natl Sci Counc. ROC $(A), 25(1): 1 \sim 16$.

Hung H H, Yang Y B. 2001b. Elastic waves in visco-elastic half-space generated by various vehicle loads [ग]. Soil Dynamics and Eartiquake Engineering, 21(1): 1 17.

Ide S. 2002. Estimation of radiated energy of finite-source earthquake models [J]. Bull Seism Soc Amer, 92(8): 2 994 3005.

Jones C J C, Sheng X, Petyt M. 2000. Simulations of ground vibration from a moving harmonic load on a railway track [J]. J Sotmd $t i b r$, 231(3): doi:10.1006/jsvi.1999.2559, 739 751.

Melke J, Kraemer S. 1983. Diagnostic methods in the control of railway noise and vibration [J]. J Sound Vibr, 87(2): 337 386.

Okumura Y, Kuno K. 1991. Statistical analysis of field data of railway noise and vibration collected in an urban area [J]. Appl Acous, 33: 263 280 ,

State Seismological Bureau. 1990. Technical Specification for Seismic Station Observation [M]. Beijing: Seismological Press, 3 24 (in Chinese).

WANG Qi-chang ed-in-chief. 1999. Civil Engineering for High-speed Railway [M]. Chengdu: Press of Southwestern Communications University, 280 292 (in Chinese).

Willmore P L ed. 1979. Mantal of Seismological Observatory Practice. World Data Center A for Solid Earth Geophysics, Report SE-20, September 1979, Boulder, Colorado, 1 165.

XIA He, WU Xuan, YU Da-ming. 1999. Environmental vibration induced by urban rail transit system [J], Journal of Northern Jiaotong University, 23(4): 1 7 (in Chinese) .

Yang Y B, Hung H H, Chang D W. 2003. Train-induced wave propagation in layered soils using finite/infinite element simulation [J]. Soil Dynamics and Earthquake Engineering, 23(4): 263 278.

ZHAI Wan-ming. 2001. Vehicle-track Coupling Dynamics [M]. Beijing: China Railway Publishing House, 1 398 (in Chinese with English abstract).

ZHENG Zhi-zhen. 1979. Fundamental of Spectrum Analysis [M]. Beijing: Seismological Press, 1 303 (in Chinese). 